\title{
Copper(II) complex of 3-cinnamalideneacetylacetone: Synthesis and characterisation
}

\author{
A VEERARAJ, P SAMI and N RAMAN* \\ Department of Chemistry, VHNSN College, Virudhunagar 626 001, India
}

MS received 4 May 2000; revised 31 July 2000

\begin{abstract}
A bidentate ligand derived from cinnamaldehyde and acetylacetone and its copper(II) complex have been synthesized and characterized by elemental analysis, UV-Vis, IR, ESR and magnetic susceptibility measurements. Magnetic susceptibility measurements, ESR and electronic spectral data indicate the presence of six coordinated $\mathrm{Cu}$ (II) ion. The ligand and complex are tested for antibacterial activity against Pseudomonas aeroginosa. They are found to show the antibacterial activity.
\end{abstract}

Keywords. $\beta$-Diketones; Knoevenagel condensate; electron spin resonance; Pseudomonas aerogenosa; Caesalpinia bonducella.

\section{Introduction}

The study of the transition metal complexes of $\beta$-diketones have been well established ${ }^{1}$. Several ligands derived from $\beta$-diketones are also known to form metal complexes. These ligands derived from $\beta$-diketones have been employed for the preparation of new complexes. The $\beta$-diketone ligands are considered as potential ligands due to their enolising ability. But being incapable of enolisation, the condensates have not perhaps been considered earlier as potential ligands towards transition metal ions. As compared to the metal $\beta$-diketone complexes, less work has been reported on metal complexes of $\beta$ diketone condensates. Therefore, it is thought worthwhile to synthesise a Knoevenagel condensate by the condensation of cinnamaldehyde and acetylacetone and prepare its $\mathrm{Cu}$ (II) complex with a view to study their spectral, magnetic and antibacterial activity. Understanding the structure and bonding of this complex help in designing and synthesizing some novel and more stable condensates of this type.

\section{Experimental}

AnalaR grade chemicals were used for the preparation of the complexes. The solvents were purified as per the procedure given in the literature ${ }^{2}$.

\subsection{Preparation of 3-cinnamalideneacetylacetone (Cinac)}

Cinnamaldehyde $(0 \cdot 1 \mathrm{M})$ was added to acetylacetone $(0 \cdot 1 \mathrm{M})$ taken in a beaker with continuous stirring. The mixture was allowed to cool at room temperature and then piperidine $(0.001 \mathrm{M})$ was added to it drop by drop with constant stirring. Stirring was

*For correspondence 
continued for further $10 \mathrm{~min}$. Then the mixture was kept in the refrigerator for $48 \mathrm{~h}$. After that the mixture was extracted with chloroform and 5\% hydrochloric acid. The mixture was vigorously shaken in a separating funnel. The organic layer consists of 3cinnamalideneacetylacetone and excess chloroform. The bottom layer was eluted and dried by magnesium sulphate to remove any water. The excess chloroform was distilled out. The ligand was collected as orange yellow semisolid and preserved in a dessicator.

\subsection{Preparation of copper complex [Cu(cinac)]}

The procedure reported ${ }^{3}$ for the preparation of $[\mathrm{Cu}(\mathrm{salacac})]$ was used with slight modification. In a typical procedure, a mixture of Cinac $(0.01 \mathrm{M})$ and 3 drops of piperidine in chloroform $(50 \mathrm{ml})$ was gradually added to a suspension of hydrated copper acetate $(0.01 \mathrm{M})$ in chloroform $(50 \mathrm{ml})$ and stirred in a round bottomed flask. The mixture was then boiled under reflux $(2-3 \mathrm{~h})$ until it became clear and then dark green. Upon concentration of the solution to one-third volume followed by the addition of petroleum ether $(100 \mathrm{ml})$ and subsequent cooling at $0^{\circ} \mathrm{C}$ for $2 \mathrm{~h}$, a bluish green coloured solid was precipitated. This product was removed by filtration, washed with $50 \%$ (V/V) ethanol-acetone mixture, dried and recrystallised from ethanol. The $\mathrm{C}, \mathrm{H}$ contents of the complex was estimated through microanalysers. The metal content of the complex was estimated gravimetrically.

\subsection{Antibacterial test method}

NCCLS approved standard nutrient agar was used as a medium for testing the susceptibility of microorganisms to the antibacterial agents.

For testing the antibacterial activity of the ligand (cinac), complex [Cu(cinac)] and that of the oil of Caesalpinia bonducella, a well diffusion method ${ }^{4}$ was used. In a typical procedure a well was made on the agar medium inoculated with Pseudomonas aeroginosa. The well was filled up with the test solution of appropriate concentration using a micropipette. The test medium was incubated for $24 \mathrm{~h}$ at $37^{\circ} \mathrm{C}$. During this period the test solution was diffused into the plate and affected the growth of the inoculated Pseudomonas aeroginosa. A zone was developed on the plate. The radius of the zone is the measure of the antibacterial activity.

A bulk of $0.1 \mathrm{mM}$ solution of cinac and [Cu(cinac)] were prepared by using DMSO as solvent and were used in our investigation. The antibacterial activity of cinac, [ $\mathrm{Cu}(\mathrm{cinac})]$ were tested for two different doses $(4 \mu \mathrm{l}$ and $6 \mu \mathrm{l})$. The oil extracted from Caesalpinia bonducella seed was used without any dilution.

\subsection{Physical measurements}

The UV-Vis spectra of the ligand and complex in the range $200-1100 \mathrm{~nm}$ were recorded on a Shimadzu model $160 \mathrm{UV}$-Vis spectrophotometer. The IR spectra of ligand and complex were recorded in the range of $4000-200 \mathrm{~cm}^{-1}$ in a Perkin-Elmer model 783 IR spectrophotometer using $\mathrm{KBr}$ disc method. ESR spectra were recorded on a Varian E109, X-band spectrometer equipped with $100 \mathrm{kHz}$ field modulation both at room temperature and liquid nitrogen temperature using methanol as solvent. Magnetic susceptibility measurements were carried out by employing Gouy method at the room temperature on powder sample of the complex. Copper sulphate was used as calibrant. 


\section{Results and discussion}

The complex, $[\mathrm{Cu}(\mathrm{cinac})]$ is bluish green in colour, non-hygroscopic, amorphous, air and photo stable powder. The observed conductance $\left(3.2 \mathrm{mho} \mathrm{cm}^{2} \mathrm{~mol}^{-1}\right)$ and magnetic moment $(1.8 \mathrm{BM})$ values suggest a monomeric 1:1 ligand to copper(II) acetate ratio for the complex molecule. The results obtained from microanalytical measurements and metal estimation data confirm the stoichiometry of the complex and suggest the formation of the complex as per the scheme 1 .

The nature of the complex is further characterized by IR, UV-Vis and ESR spectra.

\subsection{IR studies}

The IR $\gamma_{\mathrm{C}=\mathrm{O}}$ of the complex and related systems have been collected in table 1 . The complex spectrum shows three prominent peaks in the region $1610-1410 \mathrm{~cm}^{-1}$. The bands at $1610(\mathrm{sh})$ and $1590 \mathrm{~cm}^{-1}$ are assigned as $\gamma_{\mathrm{C}=0}$ and $\gamma_{\mathrm{C}=\mathrm{C}}$ vibrations respectively ${ }^{5,6}$. The observed downfield shift, going from free ligand to metal complex $\gamma_{\mathrm{C}=0}$, suggests neutral ketonic coordination of carbonyl groups to the metal (table 1). The band at $3220 \mathrm{~cm}^{-1}$ for the complex ascertains the presence of coordinated water molecule ${ }^{10}$. Further the thermal analysis shows that the complex loses two water molecules at $170^{\circ} \mathrm{C}$. This suggests the presence of two coordinated water molecules in the complex ${ }^{11}$. The IR stretching frequency observed at $1410 \mathrm{~cm}^{-1}$ in the complex has been attributed to the presence of acetate group. Hence, the proposed structure for the complex is as given in scheme 1. Furthermore, the presence of peak around $500 \mathrm{~cm}^{-1}$ for the complex is indicative of $\mathrm{Cu}-\mathrm{O}$ stretching vibrations ${ }^{3}$.

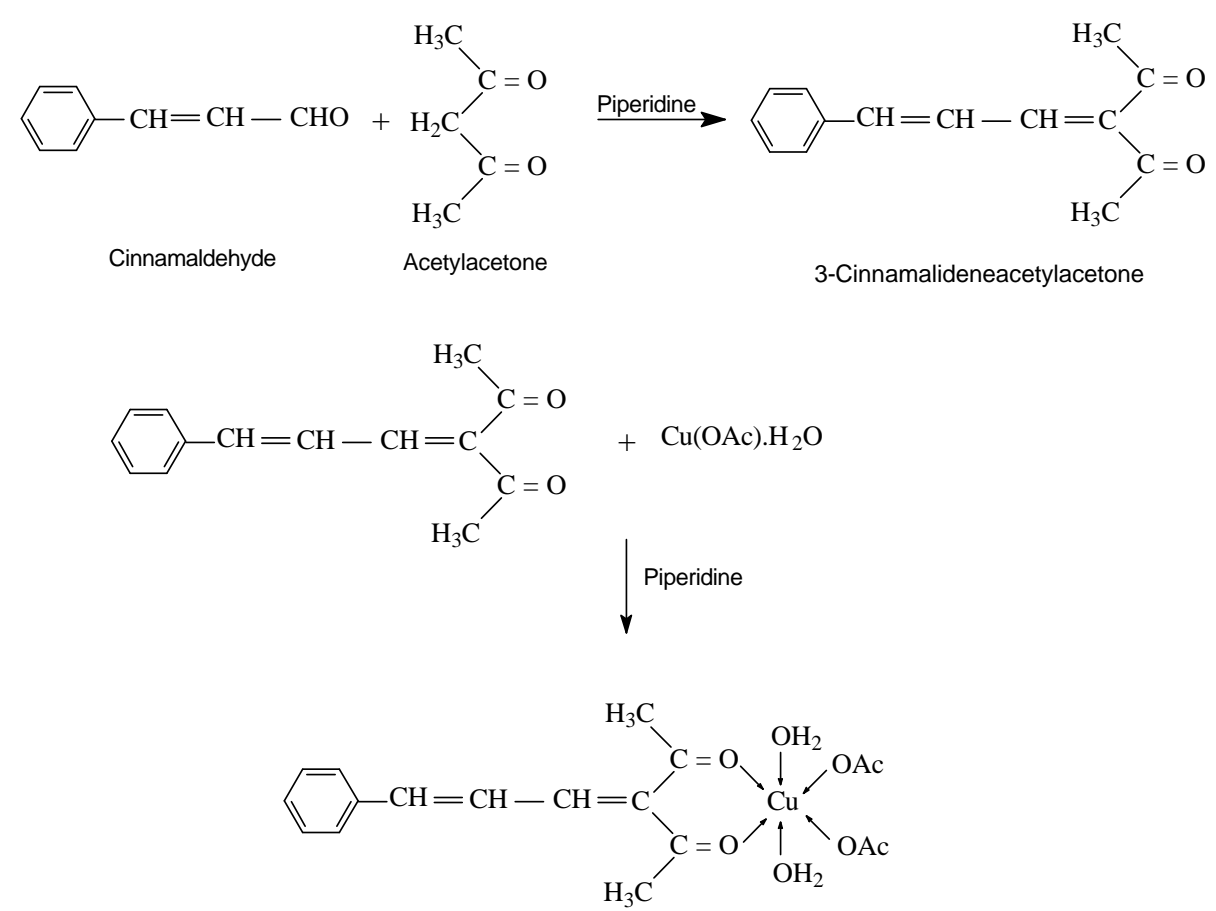

Scheme 1. 
Table 1. Shift of $\gamma_{(\mathrm{C}=0)}$ frequencies $\left(\mathrm{cm}^{-1}\right)$ upon metal ion coordination in $\beta$ diketones.

\begin{tabular}{lcccc}
\hline & \multicolumn{2}{c}{$\gamma_{(\mathrm{C}=\mathrm{O})}\left(\mathrm{cm}^{-1}\right)$} & & \\
\cline { 2 - 3 } & $\begin{array}{c}\text { Free } \\
\text { ligand } \gamma_{1}\end{array}$ & $\begin{array}{c}\text { Coordinated } \\
\text { ligand } \gamma_{2}\end{array}$ & $\begin{array}{c}\Delta \gamma \\
\left(\gamma_{1}-\gamma_{2)}\right.\end{array}$ & Reference \\
\cline { 1 - 2 } $\begin{array}{l}\text { Simple enolic, e.g. anionic } \\
\text { coordination of (acac) }\end{array}$ & 1730 & 1560 & 140 & 7,8 \\
$\begin{array}{l}\text { Simple ketonic, e.g. neutral } \\
\text { coordination of (acac) }\end{array}$ & 1730 & 1720 & 10 & 8,9 \\
$\begin{array}{l}\text { Conjugated ketonic, } \\
\text { e.g. neutral (benac) }\end{array}$ & 1705 & 1660 & 45 & 3 \\
$\begin{array}{l}\text { Title conjugated ketonic, } \\
\text { e.g. neutral (cinac) }\end{array}$ & 1700 & 1610 & 90 & Present work \\
\hline
\end{tabular}

\subsection{UV-Visible studies}

The ligand Cinac shows a single band at $30,300 \mathrm{~cm}^{-1}$ characteristic $\lambda_{\max }$ obtained from numerical calculations based on Woodward-Fieser calculation ${ }^{12}$. This confirms the structure of the ligand as given in chart 1 .

The complex $\left[\mathrm{Cu}\right.$ (cinac)] shows a broad band at $13,850 \mathrm{~cm}^{-1}$ and a sharp band at $41,490 \mathrm{~cm}^{-1}$. Disappearance of the band characteristic of the ligand Cinac at $30,300 \mathrm{~cm}^{-1}$ and appearance of a new band at $13,850 \mathrm{~cm}^{-1}$ confirm the effective coordination of the ligand with $\mathrm{Cu}^{2+}$ ion and thereby the formation of the complex.

The $d-d$ band at $13,850 \mathrm{~cm}^{-1}$ for $[\mathrm{Cu}(\mathrm{cinac})]$ is attributed to the $d_{x z}, d_{y z} \rightarrow d_{x^{2}-y^{2}}$ electronic transition. Observation of this $d-d$ transition suggests a tetragonally elongated octahedral geometry ${ }^{13,14}$ around $\mathrm{Cu}^{2+}$ in $[\mathrm{Cu}(\mathrm{cinac})]$. Further, the results are also supported by ESR studies.

\subsection{ESR studies}

The ESR spectrum of methanol solution of $[\mathrm{Cu}(\mathrm{cinac})]$ measured at X-band frequency at 300 and $77 \mathrm{~K}$ is given in figure 1 . The $300 \mathrm{~K}$ spectrum (figure 1a) shows an isotropic pattern, which is expected for $\mathrm{Cu}^{2+}$ in solution. But the spectrum for the frozen solution (figure 1b) shows usual anisotropic pattern as expected for a powder sample. The $g$ and $A$ tensors evaluated are given in table 2. ESR data of $[\mathrm{Cu}(\mathrm{cinac})]$ with related systems are also collected in table 3 for the sake of comparison.

The observation of $g_{\|}$and $g_{\perp}$ for [Cu(cinac)] suggests that the system is axially symmetric ${ }^{15}$. In axial spectra the $g$-values are related by the expression ${ }^{16}$,

$$
G=g_{\|}-2 / g_{\perp}-2 .
$$

For $[\mathrm{Cu}(\mathrm{cinac})] g_{\|}=2.3305>g_{\perp}=2.0756$ and the fact that $G=4.3$ suggests the local tetragonal axes are aligned parallel with unpaired electrons in $d_{x^{2}-y^{2}}$ orbital ${ }^{15,17}$. The ESR parameters coincide well with the other related systems (table 3). This suggests the geometry of the complex as tetragonally elongated octahedron belonging to the $D_{4 h}$ point group. 
<smiles>CC(=O)C(=CC=Cc1ccccc1)C(C)=O</smiles>

Chart 1.

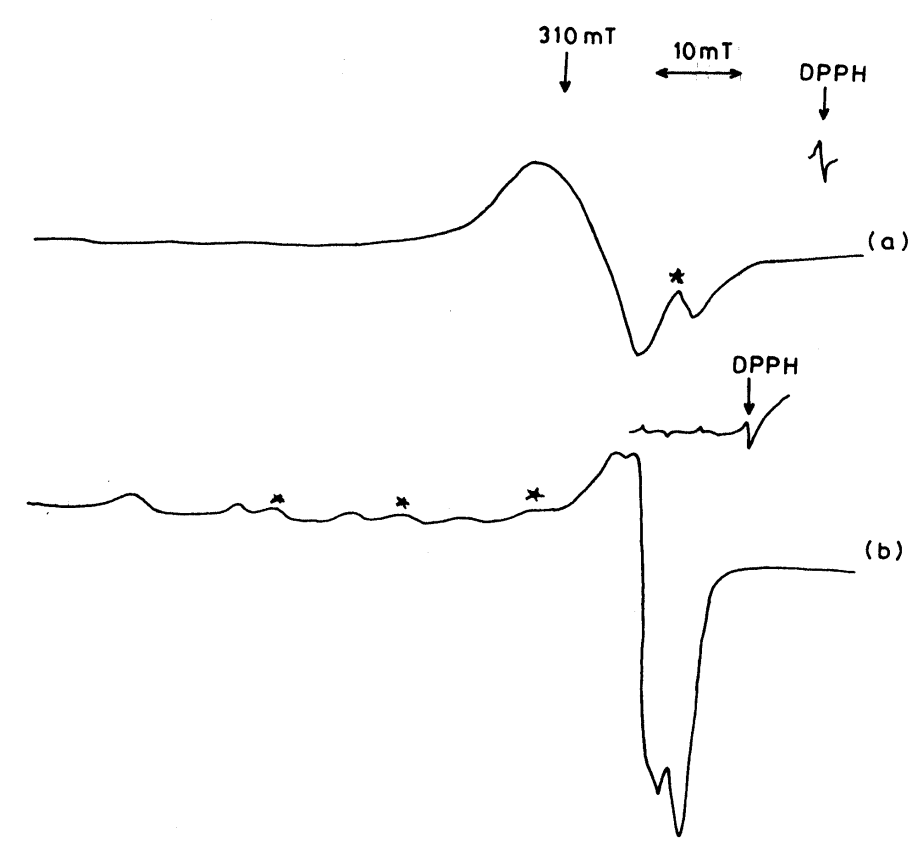

Figure 1. X-band ESR spectrum of [Cu(cinac)] measured in methanol at (a) 300, and (b) $77 \mathrm{~K}$. (*Corresponds to unidentified $\mathrm{Cu}$ species.)

For the tetragonally elongated octahedral $\mathrm{Cu}(\mathrm{II})$ complex the $g$ and $A$ tensors are given by the usual axially symmetric spin Hamiltonian.

$$
\mathrm{H}=\beta\left[g_{\|}\left(B_{z} S_{z}\right)+g_{\perp}\left(B_{x} S_{x}+B_{y} S_{y}\right)+A_{\|}\left(S_{z} I_{z}\right)+A_{\perp}\left(S_{x} I_{x}+S_{y} I_{y}\right)\right]
$$

We have used simplified molecular orbital theory ${ }^{19}$ to calculate the molecular orbital coefficients (bonding coefficients) and $\alpha^{2}, \beta^{2}$ and $\gamma^{2}$. These bonding coefficients and spin orbit coupling constants were calculated using the following expressions ${ }^{20}$,

$$
\begin{aligned}
& g_{\|}=2 \cdot 0023-8 \lambda\left(\alpha^{2} \beta^{2}\right) / \Delta E, \\
& g_{\perp}=2 \cdot 0023-2 \lambda\left(\alpha^{2} \gamma^{2}\right) / \Delta E,
\end{aligned}
$$


Table 2. ESR spectral data of $[\mathrm{Cu}(\mathrm{cinac})]$.

\begin{tabular}{lccccc}
\hline & \multicolumn{3}{c}{$g$ tensor } & & $A_{63}\left(\times 10^{-4} \mathrm{~cm}^{-1}\right), \mathrm{Cu}$ \\
\cline { 2 - 6 } Temperature $(\mathrm{K})$ & $g_{\|}$ & $g_{\perp}$ & & $A_{\|}$ & $A_{\perp}$ \\
\hline 300 & \multicolumn{2}{c}{$g_{\text {iso }}=2.1645$} & & \multicolumn{2}{c}{$A_{\text {iso }}=41.27 *$} \\
77 & 2.3305 & 2.0756 & & 171.6 & 21.70 \\
\hline
\end{tabular}

*Value calculated from linewidth

Table 3. ESR spin Hamiltonian parameters of some $\mathrm{Cu}(\mathrm{II})$ complexes having $D_{4 h}$ effective symmetry.

\begin{tabular}{lccc}
\hline Complex & $g_{\|}$ & $g_{\perp}$ & Reference \\
\hline $\mathrm{Cu}\left(\mathrm{H}_{2} \mathrm{O}\right)_{4}\left(\mathrm{HCO}_{2}\right)_{2}$ & $2 \cdot 3500$ & $2 \cdot 0600$ & 13 \\
$\mathrm{Cu}\left(\mathrm{NH}_{3}\right)_{4}\left(\mathrm{SCN}_{2}\right.$ & $2 \cdot 2370$ & $2 \cdot 0560$ & 18 \\
$\mathrm{Cu}\left(\mathrm{H}_{2} \mathrm{O}\right)_{4}\left(\mathrm{UO}_{2}\right)_{2}\left(\mathrm{AsO}_{4}\right)_{2} 4 \mathrm{H}_{2} \mathrm{O}$ & $2 \cdot 3554$ & $2 \cdot 0676$ & 17 \\
$\mathrm{Cu}\left(\mathrm{NH}_{3}\right)_{4}\left(\mathrm{NO}_{2}\right)_{2}$ & $2 \cdot 2340$ & $2 \cdot 0520$ & 17 \\
{$[\mathrm{Cu}(\mathrm{cinac})]\left(\mathrm{H}_{2} \mathrm{O}_{2}\right)_{2}(\mathrm{OAc})_{2}$} & $2 \cdot 3305$ & $2 \cdot 0756$ & Present work \\
\hline
\end{tabular}

$$
\begin{aligned}
& A_{\|}=P\left\{\left[-\alpha^{2}(4 / 7+\kappa)\right]-2 \lambda \alpha^{2}\left[4 \beta^{2} / \Delta E+3 \gamma^{2} / 14 \Delta E \alpha^{2}\right]\right\}, \\
& A_{\perp}=P\left\{\left[\alpha^{2}(2 / 7-\kappa)\right]-\left[22 \lambda\left(\alpha^{2} \gamma^{2} / 14 \Delta E\right)\right]\right\} .
\end{aligned}
$$

Hence $\lambda$ is the spin orbit coupling constant which is $-828 \mathrm{~cm}^{-1}$ for free $\mathrm{Cu}^{2+}$ ion and $\Delta E$ is the energy difference between electronic energy states.

The bonding parameters for $[\mathrm{Cu}(\mathrm{cinac})]$ are found to be $\alpha^{2}=0.9219, \beta^{2}=0.7803$ and $\gamma^{2}=0.7013$. The extent of departure of these coefficients from unity measures the extent of delocalisation of the metal electrons due to metal-ligand bonding. $\alpha^{2}$ measures $\sigma$ bonding $^{21}, \beta^{2}$ measures out-of- $(x y)$ plane $\pi$-bonding and $\gamma^{2}$ measures in- $(x y)$ plane $\pi$ bonding. In the present case, the $\alpha^{2}$ value (0.9219) indicates the slight ionic nature of the metal-ligand $\sigma$-bonding. The deviation from unity in $\beta^{2}$ and $\gamma^{2}$ values indicates the presence of considerable out-of-plane and in-plane $\pi$-bonding contribution in metal ligand $\pi$-bonding. The spin orbit coupling constants ${ }^{22} \lambda_{\|}\left(-789.87 \mathrm{~cm}^{-1}\right)$ and $\lambda_{\perp}$ $\left(-785.12 \mathrm{~cm}^{-1}\right)$ suggest greater contribution from out-of- $(x y)$ plane $\pi$-bonding than from in-plane $\pi$-bonding. Thus, ESR study of the copper complex has provided supportive evidence to the optical results.

\section{Antibacterial studies}

The complex was screened in vitro for its antibacterial activity against the gram-negative bacteria Pseudomonas aerogenosa using the diffusion method ${ }^{4}$. The antibacterial activity of the ligand was comparable with that of the medicinal oil Caeselpinia bonducella. The activity of the complex was higher than that of the ligand as well as of the oil. This identification strongly suggests the enhancement of antibacterial activity as a function of chelation. 


\section{Acknowledgements}

The authors express their sincere thanks to the Regional Sophisticated Instruments Centre, Lucknow for recording the ESR spectra. We thank the Punjab University, Chandigarh for permission and facilities to carry out the elemental analysis.

\section{References}

1. Mehrotra R C, Bohra B and Gaur D P 1978 Metal $\beta$-diketonates and allied derivatives US edn (New York: Academic Press)

2. Vogel A I 1978 Practical organic chemistry 4th edn (London: Longman-ELBS)

3. Abdul Samath S, Raman M, Raman N, Jeyasubramanian K T and Ramalingam S K 1992 Transition Met. Chem. 1713

4. Boyd R F 1998 General microbiology 2nd Int. edn (Times Mirror/Mosky College) p. 441

5. Bellamy L J 1958 The infra-red spectra of complex molecules 2nd edn (New York: Methuen)

6. Nakamoto K 1978 The infra-red spectra of inorganic and coordination compounds 3rd edn (New York: Wiley Interscience)

7. Shankar G, Paulraj K, Balasubramanian V and Ramalingam S K 1984 J. Indian Inst. Sci. 65 291

8. Abdul Samath S, Raman M and Ramalingam S K 1998 Indian J. Chem. A27 63

9. Nakamura Y, Isobe K, Morita H, Yamazaki S and Kawaguchi S 1972 Inorg. Chem. 111573

10. Hassaan Aly M A and Marei M G 1993 J. Indian Chem. Soc. 7064

11. Jeyasubramanian K, Abdul Samath S, Tambidurai S, Murugesan R and Ramalingam S K 1995 Transition Met. Chem. 2076

12. Silverstein R M, Bassler G C and Morrill T C 1981 Spectrometric identification of organic compounds 4th edn (New York: John Wiley \& Sons) p. 313

13. Billing D E and Hathaway B J 1968 J. Chem. Soc. (A) 1516

14. Billing D E, Hathaway B J and Nicholls P 1969 J. Chem. Soc. (A) 316

15. Hathaway B J and Tomlinson A A G 1970 Coord. Chem. Rev. 51

16. Procter I M, Hathaway B J and Nicholls P 1968 J. Chem. Soc. (A) 1678

17. Anthonisamy V S X and Murugesan R 1998 Chem. Phys. Lett. 287353

18. Tomlinson A A G, Hathaway B J, Billing D E and Nicholls P 1969 J. Chem. Soc. (A) 65

19. Murugesan R and Subramanian S 1984 Mol. Phys. 52129

20. Anthonisamy V S X June 1997 Structure, bonding and dynamic processes in condensed phases: An EPR study, Ph D thesis, Madurai Kamaraj University, Madurai

21. Anthonisamy V S X, Anantharam R and Murugesan R 1999 Spectrochim. Acta A55 135

22. Hathaway B J and Billing D E 1970 Coord. Chem. Rev. 5143 